\title{
Desktop Space Exploration
}

\author{
By M. Martin-Smith ${ }^{1}$ \& R. Buckland ${ }^{2}$ \\ ${ }^{1}$ General Practitioner, Hull, UK \\ ${ }^{2}$ Department of Design and Innovation, The Open University, UK
}

The Humble Space Telescope project aims to launch a small space telescope for educational and recreational purposes, in time for the New Millennium.

The arrival of the 3rd Millennium, accompanied in the United Kingdom by a Millennium Commission distributing 250 million per year of National Lottery funds for good causes and imaginative projects which would otherwise require direct funding by the taxpayer, provides a unique opportunity to design, build and operate a small but capable version of the pioneering Hubble Space Telescope.

In July 1994, a leading British newspaper with a long history of covering developments in science, launched a competition for members of the public to propose science projects to be funded by the Millennium Commission. The idea of a small satellite telescope, fitted with a CCD detector package was submitted by Dr. Martin-Smith, and won a share of the top prize. Meanwhile, Rodney Buckland, a Trustee of the National Science Centre project, took up the idea as an ideal new field site for the Centre, and has become its Project Manager.

It is well established that specialised and initially-expensive technologies - for example Schmidt-Cassegrain optics, CCD cameras, computers and the Internet - began as the advanced tools of professionals, and in time become accessible to amateurs, educators, and the public, for learning and recreation. The advent of small capable low cost satellites, as developed by Professor Martin Sweeting of Surrey University, simpler more flexible management structures promoted by Rodney Buckland at the Open University , "off the shelf" telescopes, such as Questar (a model of which is already space qualified) the phenomenal growth of the Internet, and the expansion of the small satellite launcher market combine to provide an excellent window of opportunity for placing access to space within the reach of desktop explorers at school and armchair ones at home.

Remote control of observatories, whether ground based, or in Earth orbit, is an established fact. Humble offers all this to amateurs and educators at a cost of $1 / 300$ th that of Hubble, which is used predominantly by professionals .

The Millennium Commission, looking for visionary projects to celebrate the New Millennium, thus provides the chance to launch a popular educational space and astronomy project without calling on the usual sources of public funds.

\section{The Astronomy Option}

In the UK as elsewhere, astronomy forms a part of the National Curriculum and yet students' observations are hampered by many problems. As in all industrialized countries, enjoyment of the night sky, our legitimate heritage, as well as the ability of astronomers both amateur and professional to carry out serial observations and measurements, are hampered by increasing light pollution and built-up skylines. Terrestrial weather, as any Briton will tell you, hardly helps. Furthermore, for school students already heavily loaded with study for their national curricula, astronomy, while an option, requires out-of-hours work, being mostly a nocturnal pursuit, while school classes are in the daytime. High quality amateur telescopes, equipped with CCD detectors and remote control software and facilities have been available off the shelf for the past few years. 
The round-the-clock, all-weather, high-quality, multispectral images from Humble will allow serious contributions to be made by students and amateur astronomers to a science which has large gaps left behind by the advancing wave-front of discovery. Again, it is a truism that when a problem meets an opportunity, great advances result. The threat and opportunity posed by Near Earth asteroids is perhaps a most pertinent example, forcing us to choose between annihilation and building a space faring civilization. It is generally accepted that young people find education in astronomy and space science intellectually exciting and challenging - more so, perhaps, than many other fields. Many countries, for example India and America, consciously use space programmes to stimulate pupils to take up science and technology for future careers. In the UK we must do the same.

\section{Astronomy On Line}

A taste of things to come is being promoted by The European Association for Astronomy Education (1). In November 1996, schools across Europe will be offered access, via the Internet, to ground-based observatories and other sources of astronomical data in a programme called Astronomy On-Line.

\section{The National Science Centre (NSC)}

The National Science Centre is a project to develop a national centre for public understanding of science. It will attract one million visitors a year who will be able to see real satellite operations and data acquisition and processing in action. It is also planned that school pupils will be able to participate in the Pupil Researcher Initiative programme operated by NSC partner Sheffield Hallam University (2), whereby pupils will carry out research programmes using Humble, write papers for a Humble journal, and present results to a Humble Conference. The British National Space Centre has agreed to circulate British schools nationwide with information on Humble and an invitation to participate in the user requirements capture process.

\section{Small Mission Architects and Builders}

Surrey Satellite Technology Ltd. (3), a world-leading group of small space mission architects and builders, has pronounced itself keen and capable of designing and fabricating the Humble spacecraft as funds become available, and following a feasibility study projected for September 1996. In addition, the Mullard Space Science Laboratory, Satellites International Ltd, D.R.A Farnborough, Birmingham University and the University of Kent have signified interest in providing instrumentation and other facilities for Humble.

The potential exists to equip Humble with multi- spectral capabilities, allowing observations in ultra-violet and near infra-red wavelengths from above the atmosphere. This would give non-professional users access to hitherto unfamiliar views of celestial objects, and open up the advantages of space-based astronomy to new groups.

The growth of the small launcher market over the next few years enhances the affordability and attractiveness of the project to potential supporters.

\section{Faster, Cheaper, Better}

The Atmospheric and Mesospheric Particle Transfer Experiment (AMPTE) went from concept to operational status in 3 years, as did the Clementine mission in 1994. The NEAR spacecraft, likewise achieved a three-year gestation period, within budget. It is 
against this background that a launch for Humble, before the year 2000, at a cost of 6-8 million is a reasonable proposition.

Very preliminary soundings of possible launchers have been made. Depending on the results of feasibility studies, possibilities include Ariane and Orbital Sciences Corporation's Pegasus launcher.

The National Science Centre has the management framework for success. The Centre's Trustees have considerable experience in the management of scientific and educational programmes, and plan to handle data collection and distribution from the Centre. Work is proceeding on the architectural and financial aspects of the NSC, with a view to submitting a detailed technical and business review in the autumn.

The growth of the Information Super-highway allows effective distribution of images and data from a space-based observatory - Hubble has shown the way. Humble will provide for desktop exploration in schools and universities, and armchair exploration by amateur astronomers. Many schools and institutions, as well as an increasing number of homes, have access to the Information Superhighway, with the prospect of considerable growth by the proposed launch date of Humble in late 1999. Indeed, the likely merging of large screen flat television sets and Internet linked computers in the same console makes Armchair Space Exploration an inevitable development, as shown by plans for emplacing lunar rover vehicles equipped with telepresence for entertainment as well as exploration purposes.

\section{Space for Education}

Ready access by the public to Humble imagery at the National Science Centre, on the Internet, or on participating television science programmes, will enhance peoples' appreciation of the beauties and wonders of the Heavens, as well as advance the cause of astronomical education.

In addition to giving schools and the public the opportunity to view the heavens in comfort and do real research, the Humble Space Telescope programme will allow participants to gain experience in satellite management, data acquisition, processing, and presentation of results to peer groups. Thus, a relatively small and inexpensive space programme, realisable in three years, has the potential to give millions of people access to Space.

\section{Education for Space}

The variety, quantity, and quality of observations made possible by Humble to people from many different backgrounds and walks of life will allow Humble to become more than just a small satellite in Earth orbit: all being well, it will become a Millennial institution providing many young people with the inspiration to become space professionals and creating considerable public awareness of benefits arising from space activities which has not been forthcoming in Britain.

The late Professor Hermann Oberth always hoped that space exploration and development would be carried out with popular enthusiasm. The authors hope that, in addition to its educational potential, the Humble project will foster public support for enhanced astronomical and space activities. In allowing students to conduct on-going studies of our neighbouring planets with high quality imagery, it is hoped that that Humble will inspire members of the rising generation to consider becoming space professionals and explorers.

The National Science Centre has authorised a user requirements capture process to 
be carried out starting in July 1996. It is expected that a full feasibility study will be carried out in September, as part of the National Science Centre's progression through the DAR (Detailed Appraisal Review) process for Millennium Commission funding.

British capabilities in small satellite mission execution are well established. Surrey University and its commercial affiliate Surrey Satellite Technology Ltd, have built 12 satellites to date, each within 2 years. Humble is expected to weigh about 250 kilogrammes, and to cost about 6-8 million. There will be several opportunities for demonstrating and using British space technology. Possible candidates include ion propulsion from the DRA and passive radiative cooling from the Open University.

\section{Publicity}

It is planned that Humble's potential users become aware of the project now, and begin considering its possible utilization. To this end, articles and notifications of the project have already been widely circulated. A site has been set up on the World Wide Web (3), while readers of astronomy magazines and members of societies have been notified and asked to contribute to the definition of user requirements. The international space community will also be introduced to Humble at the annual IAF gathering in October 1996 (4).

Local radio stations and several newspapers have carried features on Humble, resulting in considerable publicity. Several schools and universities have been contacted by the authors, as have conferences of physics teachers and astronomy educators in Britain and Europe. International magazines have carried articles on the project this year by one of the authors. The UK Secretary of State for Education, and her Opposition Shadows, have been acquainted with the project and its educational potential, and contact has been made with the London and Armagh Planetaria.

Many potential users are now aware of the project, and developments on the funding and feasibility studies should hasten participation. The authors plan a Humble Space Telescope Working Committee to co-ordinate the development of a user community. Through the astronomical and educational communities, the authors hope to realise a new valuable European institution, with the potential to raise seeds on Earth and beyond well into the New Millennium.

\section{REFERENCES}

1. The European Association for Astronomy Education web site is at: http://www.eso.org/astronomyonline/

2. The UK Pupil Researcher Initiatives web site is at: http://www.shu.ac.uk/schools/sci/pri/index.htm

3. A summary of Surrey Satellite Technology Ltd missions can be found at: http://www.ee.surrey.ac.uk/EE/CSER/UOSAT/missions/

4. Desktop Space Exploration, Dr. Michael Martin-Smith and Rodney Buckland, IAF-96-Q.1.08, presented at the 47th International Astronautical Congress, Beijing, China in October 1996. 